\title{
Brazilian Journal \\ of Chemical

\section{MODELING THE HIGH-PRESSURE BEHAVIOR OF BINARY MIXTURES OF CARBON DIOXIDE+ALKANOLS USING AN EXCESS FREE ENERGY MIXING RULE}

\author{
M. Castier ${ }^{1}$, L.A. Galicia-Luna ${ }^{2}$ and S.I. Sandler ${ }^{3 *}$ \\ ${ }^{1}$ Escola de Química, Universidade Federal do Rio de Janeiro, \\ Cx P. 68542, 21949-900, Rio de Janeiro - RJ, Brazil. \\ E-mail: castier@eq.ufrj.br \\ ${ }^{2}$ Instituto Politécnico Nacional, Lab. de Termodinámica para Graduados \\ ESIQIE, Edif Z, Secc 6, $1^{\text {er }}$ Piso, Mexico City 07738, DF, Mexico. \\ ${ }^{3}$ Center for Molecular and Engineering Thermodynamics, \\ Department of Chemical Engineering, University of Delaware \\ Newark - DE, 19716-3119, USA \\ Email: sandler@che.udel.edu
}

(Received: September 5, 2003 ; Accepted: June 7, 2004)

\begin{abstract}
The behavior of binary mixtures of carbon dioxide+alkanol (1-butanol, 2-butanol, 1-pentanol, or 2-pentanol) at high pressures was modeled using the Stryjek-Vera version of the Peng-Robinson equation of state. Two mixing rules were compared for this purpose: the classical one-fluid van der Waals and the Wong-Sandler mixing rules. In the case of the latter mixing rule, the NRTL model for the excess Gibbs free energy was used. We observed that both mixing rules can reproduce the qualitative aspects of the critical diagrams of these binary mixtures. A comparison of the results shows that there is no clear superiority of one mixing rule over the other in terms of the ability to predict the critical behavior of these mixtures.

Keywords: high pressure, carbon dioxide, alkanols, critical points.
\end{abstract}

\section{INTRODUCTION}

The use of carbon dioxide as extracting solvent has many advantages, such as being nontoxic, nonflammable and having a relatively mild critical temperature and pressure. A possible use of supercritical carbon dioxide is for the separation of water + alkanol mixtures. To determine proper processing conditions for such separations, it is necessary to calculate phase equilibrium at high pressures for these systems, which requires the measurement and correlation of the behavior of binary mixtures of these components. Of special interest is the behavior of binary mixtures of carbon dioxide and alkanols. Jennings et al. (1993) measured phase equilibria of carbon dioxide separately with ethanol, 1-butanol, and 1-pentanol. Lee and Lee (1998) measured the phase equilibria of the carbon dioxide +2 -pentanol mixture. More recently, GaliciaLuna and coworkers obtained phase equilibrium and critical point data for binary mixtures of carbon dioxide and different alkanols. Silva-Oliver and Galicia-Luna (2001) studied binary mixtures of carbon dioxide separately with 1-butanol and 2-

*To whom correspondence should be addressed 
butanol, Silva-Oliver et al. (2002) with 1-pentanol and 2-pentanol, and Elizalde-Solis et al. (2003) with 1-hexanol and 1-heptanol.

In this paper, we focus on the modeling of binary mixtures of carbon dioxide and an alkanol (1-butanol, 2-butanol, 1-pentanol, or 2-pentanol) using the data of Silva-Oliver and Galicia-Luna (2001) and SilvaOliver et al. (2002). The Stryjek-Vera (1986) version of the Peng-Robinson (1976) equation of state (PRSV EOS) was used. We compare the results of two mixing rules: the classical one-fluid van der Waals and the Wong-Sandler (1992) mixing rules.

\section{THERMODYNAMIC MODEL AND CRITICAL POINT CALCULATIONS}

\section{The PRSV EOS}

$$
P=\frac{R T}{v-b}-\frac{a}{v^{2}+2 b v-b^{2}}
$$

was used to model the behavior of the systems, with the $\mathrm{a}$ and $\mathrm{b}$ parameters given by

$\mathrm{a}_{\mathrm{ii}}=\frac{0.477235 \mathrm{R}^{2} \mathrm{~T}_{\mathrm{c}_{\mathrm{i}}}^{2}}{\mathrm{P}_{\mathrm{c}_{\mathrm{i}}}} \alpha_{\mathrm{PR}, \mathrm{i}}$

and

$\mathrm{b}_{\mathrm{i}}=\frac{0.077796 \mathrm{RT}_{\mathrm{c}_{\mathrm{i}}}}{\mathrm{P}_{\mathrm{c}_{\mathrm{i}}}}$

with

$\alpha_{\mathrm{PR}, \mathrm{i}}=\left[1+\kappa_{\mathrm{i}}\left(1-\sqrt{\mathrm{T}_{\mathrm{R}_{\mathrm{i}}}}\right)\right]^{2}$

where the reduced temperature is

$\mathrm{T}_{\mathrm{R}_{\mathrm{i}}}=\mathrm{T} / \mathrm{T}_{\mathrm{c}_{\mathrm{i}}}$

In the PRSV EOS, $\kappa_{i}$ is given by

$$
\kappa_{\mathrm{i}}=\kappa_{0_{\mathrm{i}}}+\kappa_{\mathrm{1}_{\mathrm{i}}}\left(1+\sqrt{\mathrm{T}_{\mathrm{R}_{\mathrm{i}}}}\right)\left(0.7-\mathrm{T}_{\mathrm{R}_{\mathrm{i}}}\right)
$$

where

$$
\begin{aligned}
& \kappa_{0_{\mathrm{i}}}=0.378893+1.4897153 \omega_{\mathrm{i}}- \\
& -0.17131848 \omega_{\mathrm{i}}^{2}+0.0196554 \omega_{\mathrm{i}}^{3}
\end{aligned}
$$

and $\kappa_{1_{i}}$ is a characteristic parameter of each component.

For our calculations, we used separately the onefluid van der Waals mixing rules and the WongSandler (1992) mixing rules. The one-fluid van der Waals mixing rules are

$a=\sum_{i=1}^{n_{c}} \sum_{j=1}^{n_{c}} x_{i} x_{j} \sqrt{a_{i i} a_{j j}}\left(1-k_{i j}\right)$

$\mathrm{b}=\sum_{\mathrm{i}=1}^{\mathrm{n}_{\mathrm{c}}} \mathrm{x}_{\mathrm{i}} \mathrm{b}_{\mathrm{i}}$

The Wong-Sandler mixing rules are

$\mathrm{a}=\frac{\mathrm{RTQ}_{\mathrm{ws}} \mathrm{D}_{\mathrm{ws}}}{1-\mathrm{D}_{\mathrm{ws}}}=\mathrm{RTD}_{\mathrm{ws}} \mathrm{b}$

$\mathrm{b}=\frac{\mathrm{Q}_{\mathrm{ws}}}{1-\mathrm{D}_{\mathrm{ws}}}$

where

$\mathrm{D}_{\mathrm{ws}}=\frac{\mathrm{a}_{\infty}^{\mathrm{E}}}{\mathrm{cRT}}+\sum_{\mathrm{i}=1}^{\mathrm{n}_{\mathrm{c}}} \frac{\mathrm{x}_{\mathrm{i}} \mathrm{a}_{\mathrm{ii}}}{\mathrm{RT} b_{\mathrm{i}}}$

$Q_{w s}=\sum_{i=1}^{n_{c}} \sum_{j=1}^{n_{c}} x_{i} x_{j}\left(b-\frac{a}{R T}\right)_{i j}$

Parameter $\mathrm{c}$ is characteristic of each equation of state, equal to -0.62323 for the PRSV EOS. In Eq. (12), $a_{\infty}^{E}$ represents the molar excess Helmholtz free energy at infinite pressure, which was calculated using the NRTL (Renon and Prausnitz, 1968) excess free energy model. The following combining rule for the term

$\left(\mathrm{b}-\frac{\mathrm{a}}{\mathrm{RT}}\right)_{\mathrm{ij}}$ was employed:

$\left(b-\frac{a}{R T}\right)_{i j}=\frac{b_{i}+b_{j}}{2}-\frac{\sqrt{a_{i i} a_{j j}}\left(1-k_{i j}\right)}{R T}$ 
Additional details about the Wong-Sandler mixing rule can be found in the original reference (Wong and Sandler, 1992). Its use for calculation of the critical point of mixtures is discussed in the work of Castier and Sandler $(1997 \mathrm{a}, \mathrm{b})$. The procedure uses a modified version of the Hicks and Young (1977) algorithm to determine possible multiple critical points for each composition and refines the solutions with the Heidemann and Khalil (1980) procedure. The critical points reported here passed the local and global stability tests for the possible appearance of additional fluid phases; the unlikely possibility of forming solid phases was not tested in our implementation.

\section{PARAMETER FITTING AND CRITICAL POINT CALCULATIONS}

Parameters of the pure components used in the PRSV EOS were taken from Stryjek and Vera (1986), with the exception of those for 2-pentanol, whose properties were not available in that reference. For this component, the values used for the critical properties and acentric factor $\left(\mathrm{T}_{\mathrm{c}}=560.4 \mathrm{~K}\right.$, $P_{c}=38.7$ bar , $\omega=0.5724$ ) are those adopted by Lee and Lee (1998). The value of the $\kappa_{1_{\mathrm{i}}}$ parameter in the PRSV EOS was fitted using the procedure developed by Orbey and Sandler (1998) using vapor pressure data compiled by Boublík et al. (1973). A $\kappa_{1_{\mathrm{i}}}$ value of 0.433 was determined in this way.
Binary interaction parameters were fitted from the VLE data. These parameters were estimated using modified versions of the parameter fitting program originally developed by Orbey and Sandler (1998) to take into account the possibility of simultaneously using data sets at different temperatures. The following objective function was used:

$\mathrm{f}=\sum_{\mathrm{j}=1}^{\mathrm{n}_{\mathrm{p}}}\left|\mathrm{P}_{\mathrm{j}}^{\mathrm{c}}-\mathrm{P}_{\mathrm{j}}^{\mathrm{e}}\right|$

where $P_{j}^{c}$ and $P_{j}^{e}$ respectively denote the calculated and measured values of the pressure at experimental point $\mathrm{j}$. Points that caused a numerical problem in the parameter fitting procedure, such as lack of convergence, were removed from the data sets used for parameter fitting. These were usually the data points at the highest pressures, where obtaining convergence is difficult. No critical point data on the mixture were used in the parameter fitting procedures, nor were data points for three-phase equilibria. However, we did observe that for the Wong-Sandler mixing rule, several different parameter sets produced very similar VLE results for some systems. In such cases the parameter set chosen for the critical point calculations was the one that produced the best representation of the critical data based on a visual analysis. A similar problem did not arise when fitting the single parameter in the van der Waals one-fluid mixing rule. The values of the fitted parameters are shown in Tables 1 and 2.

\section{Table 1: Parameters for the Systems Studied: PRSV EOS using the van der Waals mixing rule}

\begin{tabular}{|c|c|c|}
\hline Component 1 & Component 2 & $\mathbf{k}_{\mathbf{1 2}}$ \\
\hline Carbon dioxide & 1-butanol & 0.0237 \\
Carbon dioxide & 2-butanol & 0.0304 \\
Carbon dioxide & 1-pentanol & -0.0843 \\
Carbon dioxide & 2-pentanol & 0.0630 \\
\hline
\end{tabular}

Table 2: Parameters for the Systems Studied: PRSV EOS + NRTL, using the Wong-Sandler mixing rule. The non randomness parameter $(\alpha)$ of the NRTL model was set equal to 0.3 in all cases.

\begin{tabular}{|c|c|c|c|c|}
\hline Component 1 & Component 2 & $\mathrm{g}_{21} / \mathrm{R}(\mathrm{K})$ & $\mathrm{g}_{21} / \mathrm{R}(\mathrm{K})$ & $\mathrm{k}_{12}$ \\
\hline Carbon dioxide & 1-butanol & 163.40 & 85.66 & 0.0702 \\
Carbon dioxide & 2-butanol & 119.46 & 79.36 & 0.0730 \\
Carbon dioxide & 1-pentanol & -154.79 & 264.56 & 0.0462 \\
Carbon dioxide & 2-pentanol & 216.58 & 146.24 & 0.0255 \\
\hline
\end{tabular}


The results for the four binary mixtures are shown in Figures 1 to 4. The PRSV EOS using either the van der Waals one-fluid mixing rule or the Wong-Sandler mixing rule correctly predicted the qualitative aspects of the critical loci of the four mixtures. For the systems carbon dioxide $+1-$ butanol (Fig. 1) and carbon dioxide + 2-butanol (Fig. 2), the two mixing rules produced very similar results, even though the Wong-Sandler mixing rule contains two additional parameters. In the case of the carbon dioxide + 1-pentanol mixture (Fig. 3), the temperature-mole fraction (T- $\mathrm{x}$ ) projection (Fig. 3b) and the pressure-mole fraction ( $\mathrm{P}-\mathrm{x})$ projection (Fig. 3c) are marginally better represented by the Wong-Sandler mixing rule, whereas the pressure-temperature (P-T) projection (Fig. 3a) is slightly better represented by the van der Waals one-fluid mixing rule. For the carbon dioxide +2 -pentanol (Fig. 4) mixture, the $\mathrm{T}$ - $\mathrm{x}$ projection (Fig. $4 \mathrm{~b}$ ) is slightly better represented by the van der Waals mixing rule, while the P-x and T-P projections (Fig. 4a and c) are somewhat better represented by the WongSandler mixing rule.

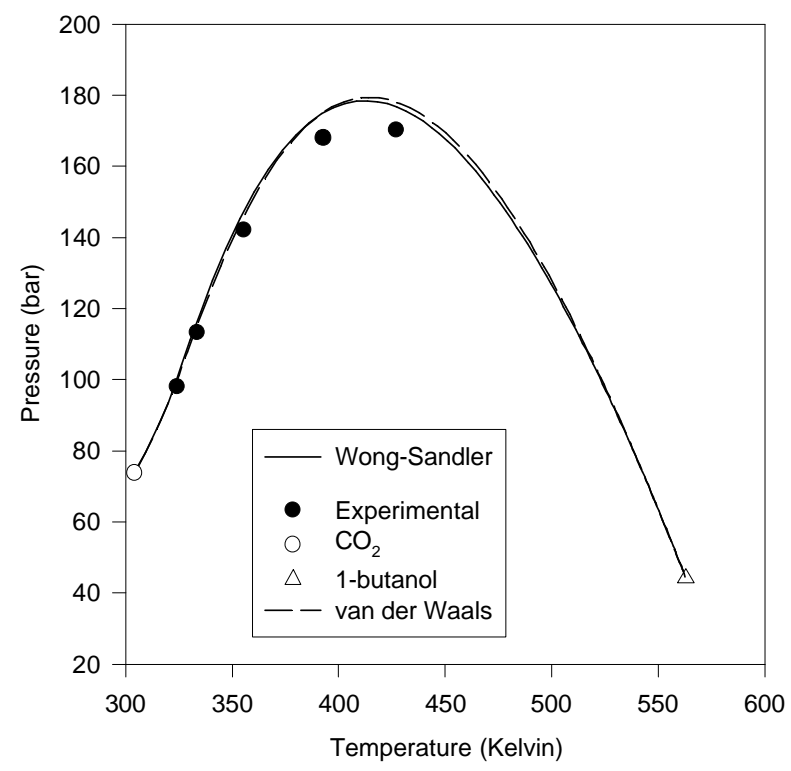

Figure 1: Critical curve of the system carbon dioxide+1-butanol: pressure-temperature projection (PRSV EOS with the one-fluid van der Waals and the Wong-Sandler mixing rules).

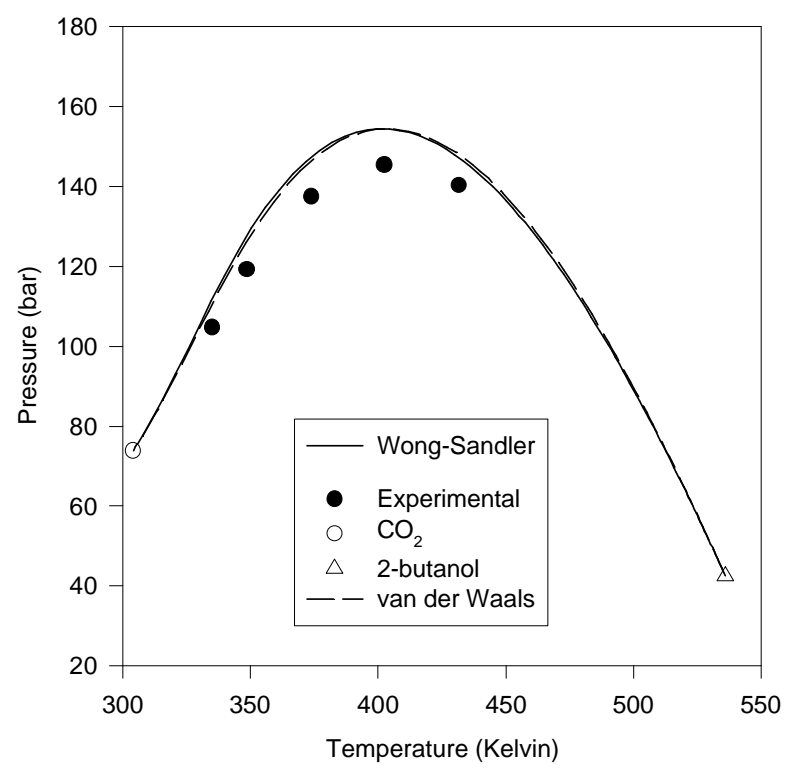

Figure 2: Critical curve of the system carbon dioxide+2-butanol: pressure-temperature projection (PRSV EOS with the one-fluid van der Waals and the Wong-Sandler mixing rules). 


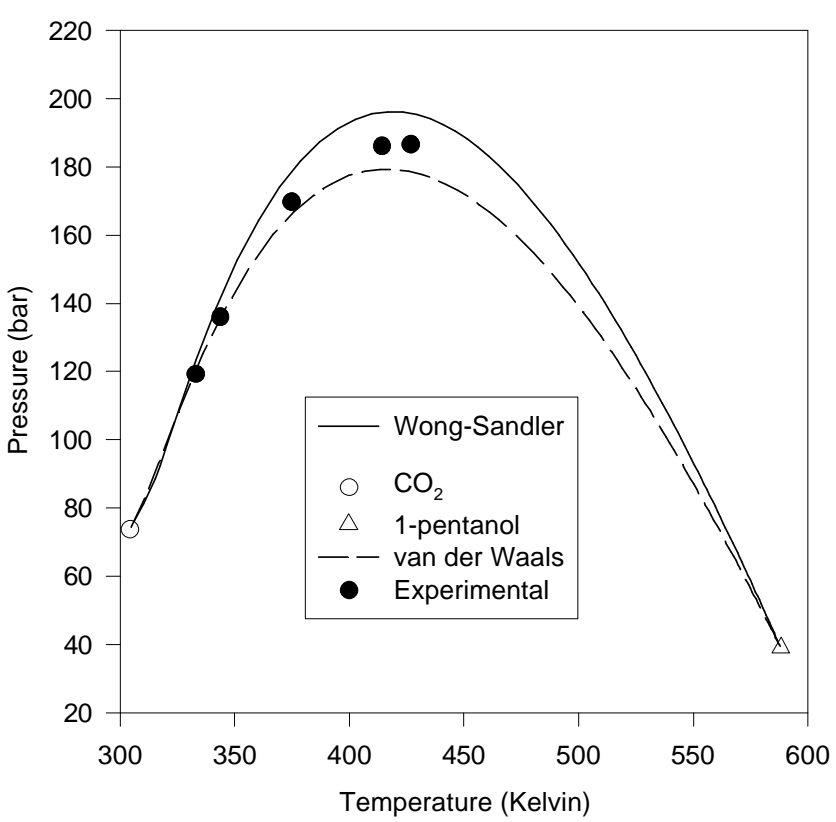

(a)

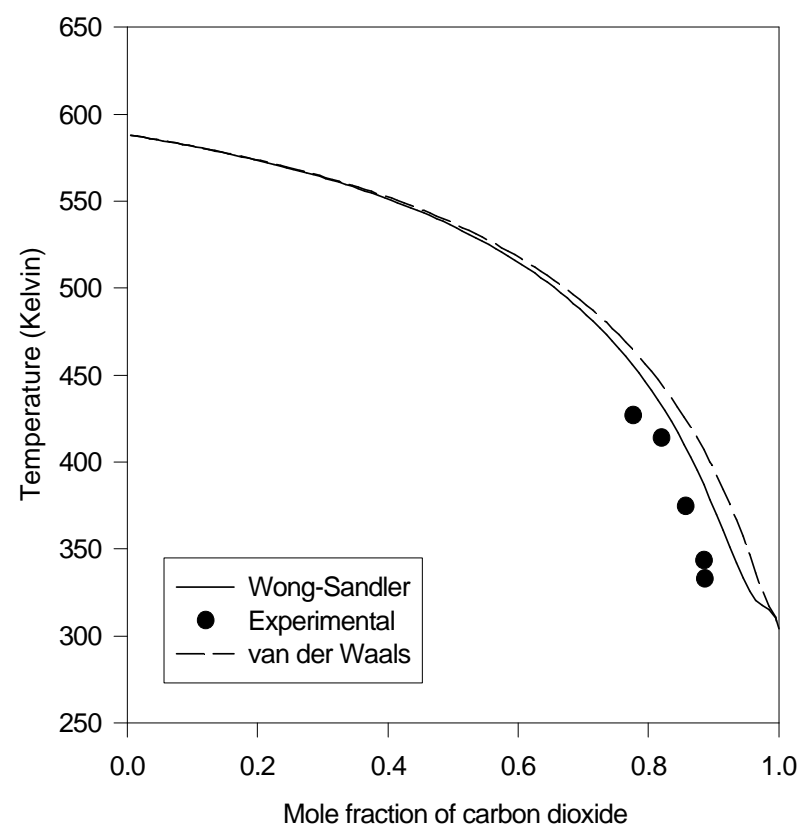

(b)

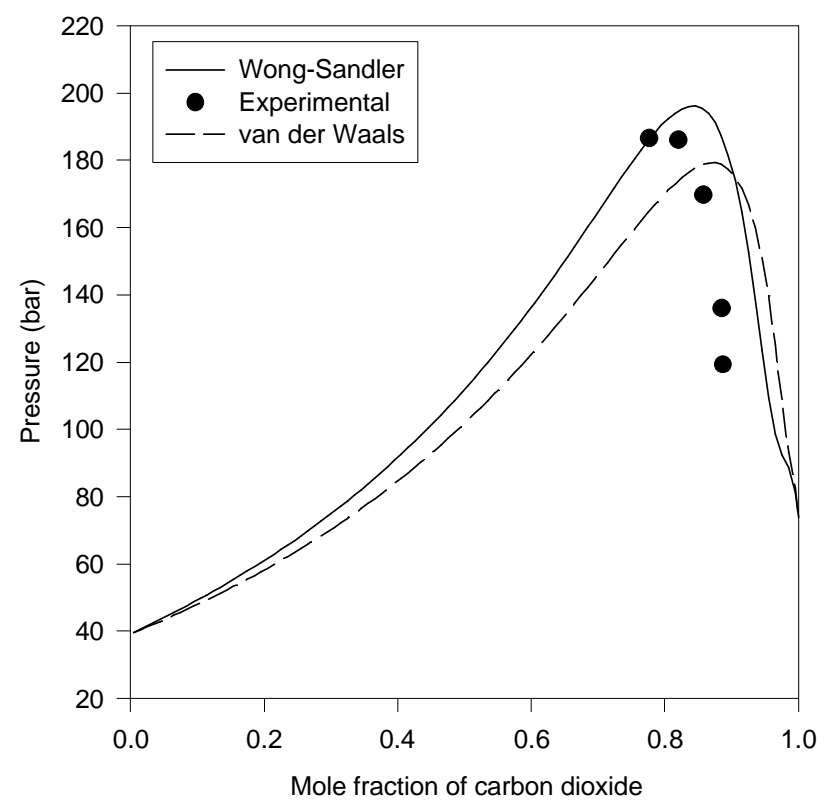

(c)

Figure 3: Critical curve of the system carbon dioxide+1-pentanol: pressure-temperature (a), temperature-mole fraction (b), and pressure-mole fraction (c) projections (PRSV EOS with the one-fluid van der Waals and the Wong-Sandler mixing rules). 


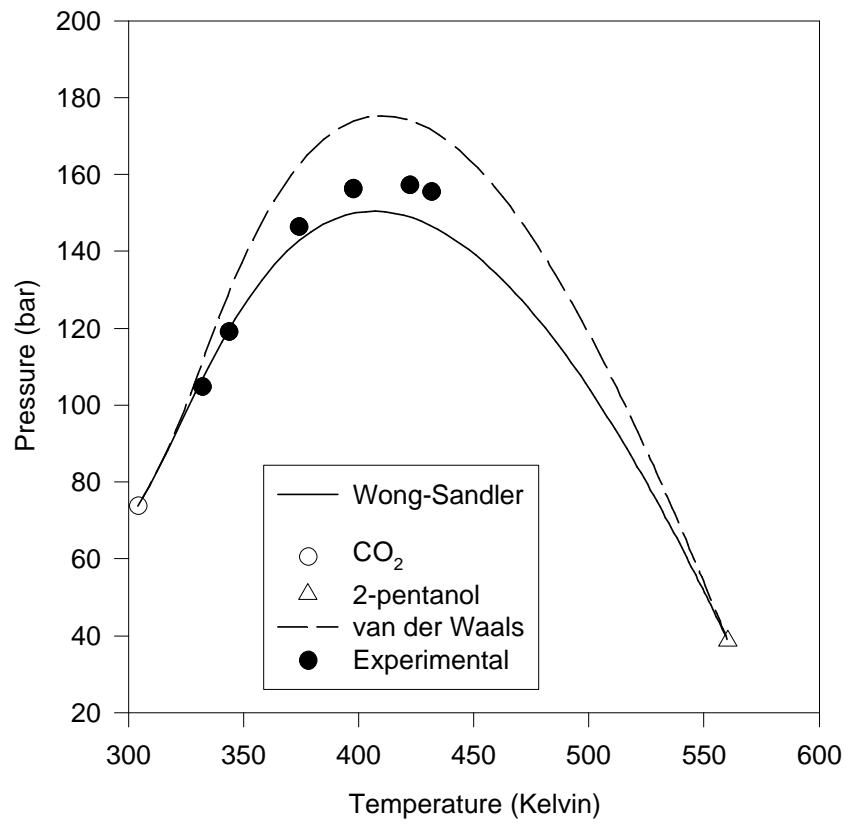

(a)

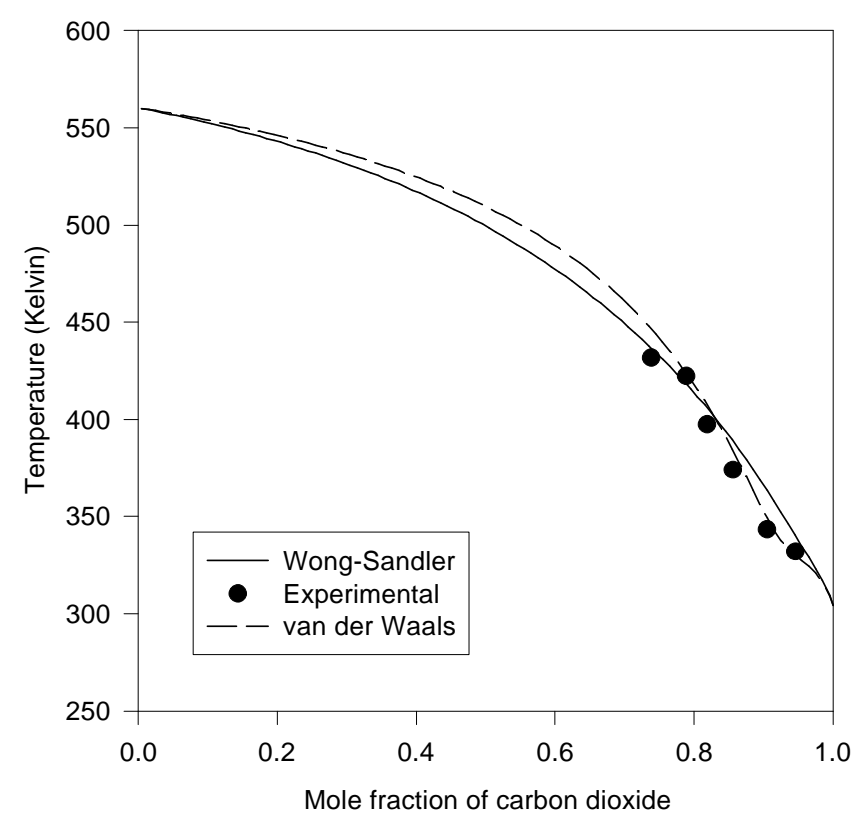

(b)

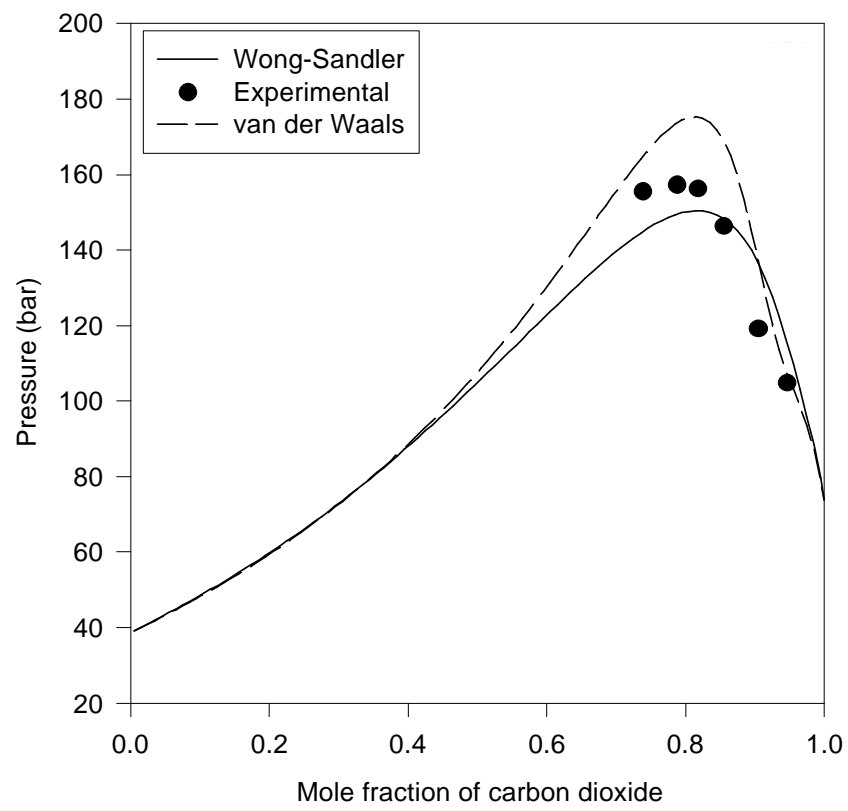

(c)

Figure 4: Critical curve of the system carbon dioxide+2-pentanol: pressure-temperature (a), temperature-mole fraction (b), and pressure-mole fraction (c) projections (PRSV EOS with the one-fluid van der Waals and the Wong-Sandler mixing rules). 


\section{CONCLUSIONS}

Four binary mixtures containing carbon dioxide and an alkanol (1-butanol, 2-butanol, 1-pentanol, or 2-pentanol), whose high-pressure phase equilibrium data had recently been measured, were modeled using the Stryjek-Vera version of the Peng-Robinson equation of state. For prediction of the critical points of these mixtures, two mixing rules were tested: the classical one-fluid van der Waals and the Wong-Sandler mixing rules. Both mixing rules can reproduce the qualitative aspects of the critical diagrams of these binary mixtures at about the same level of accuracy. Consequently, for these mixtures the simpler van der Waals one-fluid mixing rule is preferred.

\section{ACKNOWLEDGMENTS}

M.C. acknowledges the financial support of CNPq/Brazil, PRONEX (Grant 124/96), and FAPERJ.

\section{NOMECLATURE}

a molar Helmholtz free energy or EOS attractive parameter

b EOS covolume parameter

c characteristic parameter of the equation of state ( $\cong-0.62323$ for PRSV EOS)

$\mathrm{D}_{\mathrm{ws}} \quad$ auxiliary parameter of the WongSandler mixing rule

f objective function for parameter estimation

$\mathrm{g}_{\mathrm{ij}} \quad$ interaction parameter in the NRTL (original or modified) model

$\mathrm{k}_{\mathrm{ij}} \quad$ binary interaction parameter

$\mathrm{n}_{\mathrm{c}} \quad$ number of components

$n_{p} \quad$ number of experimental data points

$\mathrm{P} \quad$ pressure

$\mathrm{Q}_{\mathrm{ws}}$ auxiliary parameter of the WongSandler mixing rule

$\mathrm{R} \quad$ universal gas constant

$\mathrm{T}$ temperature

$v \quad$ molar volume

$\mathrm{x}_{\mathrm{i}} \quad$ mole fraction of component $\mathrm{i}$

\section{Greek Letters}

$\alpha$

NRTL nonrandomness parameter

$\begin{array}{ll}\alpha_{\mathrm{PR}} & \begin{array}{l}\text { auxiliary term in the Peng-Robinson } \\ \text { equation of state }\end{array} \\ \omega & \text { acentric factor } \\ \kappa & \text { parameter of the PRSV equation } \\ \kappa_{0,} \kappa_{1} & \text { parameters of PRSV equation }\end{array}$

\section{Subscripts}

c critical property

$\mathrm{i}, \mathrm{j}$ refer respectively to components $\mathrm{i}$ and $\mathrm{j}$

$\mathrm{R} \quad$ reduced property

$\infty \quad$ property at infinite pressure

\section{Superscripts}

$\begin{array}{ll}\mathrm{c} & \text { calculated } \\ \mathrm{e} & \text { experimental } \\ \mathrm{E} & \text { excess property } \\ \text { EOS } & \text { equation of state }\end{array}$

\section{REFERENCES}

Boublík, T., Fried, V., and Hála, E., The Vapour Pressures of Pure Substances, Elsevier, Amsterdam (1973).

Castier, M. and Sandler, S.I, Critical Points with the Wong-Sandler Mixing Rule. Part I: Calculations with the van der Waals Equation of State, Chem. Engng Sci. 52, 3393 (1997a).

Castier, M. and Sandler, S.I., Critical Points with the Wong-Sandler Mixing Rule. Part II: Calculations with a Modified Peng-Robinson Equation of State, Chem. Engng Sci. 52, 3579 (1997b).

Elizalde-Solis, O., Galicia-Luna, L.A., Sandler, S.I., and Sampayo-Hernandez, J.G., Vapor-Liquid Equilibria and Critical Points of the $\mathrm{CO}_{2}+1$ Hexanol and $\mathrm{CO}_{2}+1-$ Heptanol Systems, Fluid Phase Equilibria, 210 (2), 215 (2003).

Heidemann, R.A. and Khalil, A.M., The Calculation of Critical Points, AIChE J. 26, 769 (1980).

Hicks, C.P. and Young, C.L., Theoretical Predictions of Phase Behaviour at High Temperatures and Pressures for Non-Polar Mixtures: 1. Computer Solution Techniques and Stability Tests, J. Chem. Soc., Faraday II, 73, 597 (1977).

Jennings, D.W., Gude, M.T., and Teja A.S., HighPressure Vapor-Liquid-Equilibria in CarbonDioxide and 1-Alkanol Mixtures, ACS Symposium Series, 514, 10 (1993). 
Lee, H.-S. and Lee, H., High-pressure Phase Equilibria for the Carbon Dioxide-2-Pentanol and Carbon Dioxide-Water-2-Pentanol Systems, Fluid Phase Equilibria, 150-151, 695 (1998).

Orbey, H. and Sandler, S.I., Modeling Vapor-Liquid Equilibria: Cubic Equations of State and Their Mixing Rules, Cambridge Univ. Press, Cambridge (1998).

Peng, D.Y. and Robinson, D.B., A New Twoconstant Equation of State, Ind. Eng. Chem. Fundamentals 15, 59 (1976).

Renon, H. and Prausnitz, J.M., Local Compositions in Thermodynamic Excess Functions for Liquid Mixtures, AIChE J., 14, 135 (1968).

Silva-Oliver, G. and Galicia-Luna, L.A., VaporLiquid Equilibria Near Critical Point and Critical
Points for the $\mathrm{CO}_{2}+1-\mathrm{Butanol}$ and $\mathrm{CO}_{2}+2$-Butanol Systems at Temperatures from 324 to $432 \mathrm{~K}$, Fluid Phase Equilibria, 182 (1-2), 145 (2001).

Silva-Oliver, G., Galicia-Luna, L.A., and Sandler, S.I., Vapor-Liquid Equilibria and Critical Points for the Carbon Dioxide+1-Pentanol and Carbon Dioxide+2-Pentanol Systems at Temperatures from 332 to $432 \mathrm{~K}$, Fluid Phase Equilibria, 200 (1), 161 (2002).

Stryjek, R. and Vera, J.H., PRSV: An Improved Peng-Robinson Equation of State for Pure Compounds and Mixtures, Can. J. Chem. Engng. 64, 323 (1986).

Wong, D.S.H. and Sandler, S.I., A Theoretically Correct Mixing Rule for Cubic Equations of State, AIChE J., 38, 671 (1992). 